\title{
Novel method for determination of sodium in foods by thermometric endpoint titrimetry (TET)
}

\author{
Thomas Smith $^{1^{*}}$, Christian Haider ${ }^{2}$ \\ ${ }^{1}$ Antom Technologies Pty Ltd., Brisbane, Australia; *Corresponding Author: labrat@antomtechnologies.com \\ ${ }^{2}$ Titration Competence Center, Metrohm AG, Herisau, Switzerland
}

Received November 2013

\begin{abstract}
A novel yet simple, rapid and robust thermometric endpoint titration (TET) method for the determination of sodium in various foodstuffs is described. Sodium reacts exothermically with aluminium in the presence of an excess of potassium and fluoride ions to form $\mathrm{NaK}_{2} \mathrm{AlF}_{6}$ ("elpasolite"). This reaction forms the basis of a robust, reliable analytical procedure suitable for routine process control. The reaction of calcium under similar conditions (to form $\mathrm{KCaAIF}_{6}$ ) suggests that potentially, calcium may interfere in the determination of sodium in some foodstuffs. Results of an investigation suggest that at molar ratios $[\mathrm{Ca}] /[\mathrm{Na}]<0.85$, an error of $<1 \%$ of the measured value of sodium is incurred.
\end{abstract}

\section{KEYWORDS}

\section{Sodium; Titration; Food; Foodstuffs; TET;} Thermometric Endpoint Titration; Elpasolite

\section{INTRODUCTION}

In recent times, the negative impact of high levels of dietary sodium on human health outcomes has attracted increased attention from public health regulatory authorities. In many jurisdictions, there is a requirement for food manufacturers to state the total sodium content of the product on the package. To this time, sodium in foodstuffs has been analyzed by spectroscopic techniques such as flame photometry, inductively-coupled plasma spectroscopy (ICP) and atomic absorption spectroscopy (AAS), or by ion selective electrode (ISE), gravimetry or titrimetry.

The spectroscopic procedures mentioned previously require extensive sample dilution to bring the analyte concentration into a suitable range for measurement, and require careful sample clean-up to avoid nebulizer and burner blockage. Further, a significant financial barrier for smaller laboratories is the provision and maintenance of gas supplies and fume extraction equipment. Ion selective electrode measurement has to contend with interferences and changes in sodium ion activity with respect to the composition of the sample matrix. Gravimetric procedures generally suffer by being slow and demanding of high skill levels by analysts.

As an analytical chemistry technique, titration has an advantage over spectroscopic and ion analysis methods as it exhibits a linear (rather than logarithmic) response to changes in concentration of the analyte. To date, the main titration method for sodium has been analysing the chloride content by argentometric titration with standard silver nitrate and infer the sodium content from the stoichiometry of sodium chloride. This approach suffers from two significant sources of error. Firstly, not all sodium in a food has chloride as a counter-ion. Manufacturers routinely add salts of sodium for many purposes, for instance as preservatives, stabilizers, emulsifiers and flavour enhancers. Additionally, there are non-sodium chloride sodium sources from the foods themselves. For instance, a modern trend is to substitute a portion of the sodium chloride additive with potassium chloride in order to maintain a level of "saltiness" in the flavour profile while reducing the sodium impact of the product. Thus, in spite of its simplicity, the titrimetric determination of sodium by calculation from the chloride content is considered no longer acceptable. Titrimetric procedures for the determination of sodium ion itself, based on the insolubility of sodium zinc uranyl acetate have been proposed $[1,2]$ but have clearly not found favour with users over the years. Similarly, a complexometric procedure [3] does not appear to be in routine use.

Sajó [4] proposed a direct-injection enthalpimetric method for the determination of sodium. This method relied on the exothermic precipitation of $\mathrm{NaK}_{2} \mathrm{AlF}_{6}$ (elpasolite), with the temperature increase of the test solution correlated to the amount of sodium present. The reaction:

$$
\mathrm{Na}^{+}+2 \mathrm{~K}^{+}+\mathrm{Al}^{3+}+6 \mathrm{~F}^{-} \leftrightarrow \mathrm{NaK}_{2} \mathrm{AlF}_{6}
$$

is simple and occurs stoichiometrically, but as described, 
Sajó's procedure is difficult and complex, requiring highly accurate calorimetric measurements and the use of hydrofluoric acid and platinum vessels. It is not suitable for routine measurements by the less-skilled operators employed in many quality control laboratories today.

In contrast to enthalpimetric measurement methods, thermometric titrimetry is a technique which is able to utilize the near-universal property of enthalpy change in chemical reactions in a relatively easy-to-use manner. Thermometric titrations are readily automated, and share with other automated titration techniques the use of a sensor to detect the endpoint of the titration reaction. In the case of thermometric titrimetry, the sensor is a thermometer. The temperature sensing element is a thermistor, a solid-state device which exhibits relatively large changes in its resistance as a function of temperature. The thermistor forms one arm of Wheatstone bridge, and the analogue output is converted to a digital signal and transferred by an electronic interface to a computer for processing. The actual temperature of the solution is immaterial, as the sensor is only required to detect the change in solution temperature at the endpoint. For this reason, there is no need to calibrate the sensor. Further, sensor maintenance is minimal, and it is normally stored dry between titrations. It is thus a technique suitable for use in many industrial situations.

The challenge was to utilize the chemistry pioneered by Sajó and to convert it into a relatively easy titration method, suitable for use in routine process and quality control in food manufacturing facilities. It was found that the only viable method employs a titrant solution comprising aluminium ions accompanied by potassium ions in a concentration ratio such that the molar ratio $[\mathrm{Al}] /[\mathrm{K}]$ was $1: 2.2$, that is, a $10 \%$ molar excess over the stoichiometric ratio of $1: 2$ in $\mathrm{NaK}_{2} \mathrm{AlF}_{6}$. Fully-dissociated aluminium ion, $\mathrm{Al}^{3+}$ is the operating ion in the titrant, and is the one against which the titrant is standardized. The excess of fluoride ion required to drive the reaction equilibrium to the right is provided in the titration solution by either ammonium hydrogen difluoride, $\mathrm{NH}_{4} \mathrm{~F} \cdot \mathrm{HF}$ or ammonium fluoride, $\mathrm{NH}_{4} \mathrm{~F}$. While $\mathrm{NH}_{4} \mathrm{~F} \cdot \mathrm{HF}$ also buffers the titration solution to a near-ideal $\mathrm{pH} 3, \mathrm{NH}_{4} \mathrm{~F}$ can be used in combination with acids such as hydrochloric, acetic and trichloroacetic according to the circumstances of sample preparation, and may be preferred by some analysts.

\section{EXPERIMENTAL}

\subsection{Apparatus}

Thermometric titration measurements were made with a Metrohm 859 Titrotherm thermometric titration system (Herisau, Switzerland) fitted with a Metrohm 6.9011.040 Thermoprobe fluoride-resistant sensor. Automated titra- tions were carried out in polypropylene vessels mounted in the rack of a Metrohm 814 Sample Processor.

Sample preparation included comminution and disintegration. A small “inverted cup” style of kitchen blender was used to render some samples to a suitable size for representative sampling, and a Polytron PT1300 D high shear disintegrator (VWR, Germany) was used to fluidize the sample and obtain maximum extraction of the analyte.

\subsection{Reagents}

All reagents were of analytical grade.

Titrant: $\mathrm{c}\left(\mathrm{Al}^{3+}\right)=0.5 \mathrm{~mol} / \mathrm{L}, \mathrm{c}\left(\mathrm{K}^{+}\right)=1.1 \mathrm{~mol} / \mathrm{L}$, prepared from aluminium nitrate $\mathrm{Al}\left(\mathrm{NO}_{3}\right)_{3} \cdot 9 \mathrm{H}_{2} \mathrm{O}$ and potassium nitrate, $\mathrm{KNO}_{3}$.

Buffer/conditioning reagent: c(NHF.HF) $=300 \mathrm{~g} / \mathrm{L}$ ammonium hydrogen difluoride, or alternatively, $\mathrm{c}\left(\mathrm{NH}_{4} \mathrm{~F}\right)$ $=400 \mathrm{~g} / \mathrm{L}$ ammonium fluoride.

pH adjuster, sample digestion and sodium liberation aids: glacial acetic acid, trichloroacetic acid.

Solvents: toluene, acetone, deionized water.

Standard solution: $\mathrm{c}(\mathrm{NaCl})=0.25 \mathrm{~mol} / \mathrm{L}$, prepared from sodium chloride freshly dried for 4 hours at $110^{\circ} \mathrm{C}$.

\subsection{Titrant Standardization}

The titrant is standardized against a standard sodium solution, prepared from sodium chloride. A titration program was prepared to automatically dispense aliquots of increasing volumes of standard $\mathrm{NaCl}$ into successive vessels placed in the rack of the sample processor. Each titration vessel contained $5 \mathrm{~mL} c\left(\mathrm{NH}_{4} \mathrm{~F}\right)=400 \mathrm{~g} / \mathrm{L}$ and 1 $\mathrm{mL}$ concentrated $\mathrm{HCl}$, with deionized water added such that the total volume of fluid (including the $\mathrm{NaCl}$ aliquot) approximated $30 \mathrm{~mL}$. The titration program automatically computed the molarity, systematic error of the determination and the coefficient of correlation from a regression analysis of the results. Figure 1 illustrates the process by which the titrant molarity and systematic error is calculated.

This procedure provides assurance that the method is linear over the anticipated range of sodium values to be measured, and also determines its systematic error. The systematic error incorporates all error sources inherent in the determination, including sodium impurities in the reagents. The systematic error is equal to the value of the $y$ axis intercept in the linear relationship, and in this instance was calculated to be $0.070 \mathrm{~mL}$.

\subsection{Determination of Systematic Error}

For accurate estimation of analytes in samples by TET, it is important to determine the systematic error of the analysis as applied to the sample under investigation. 


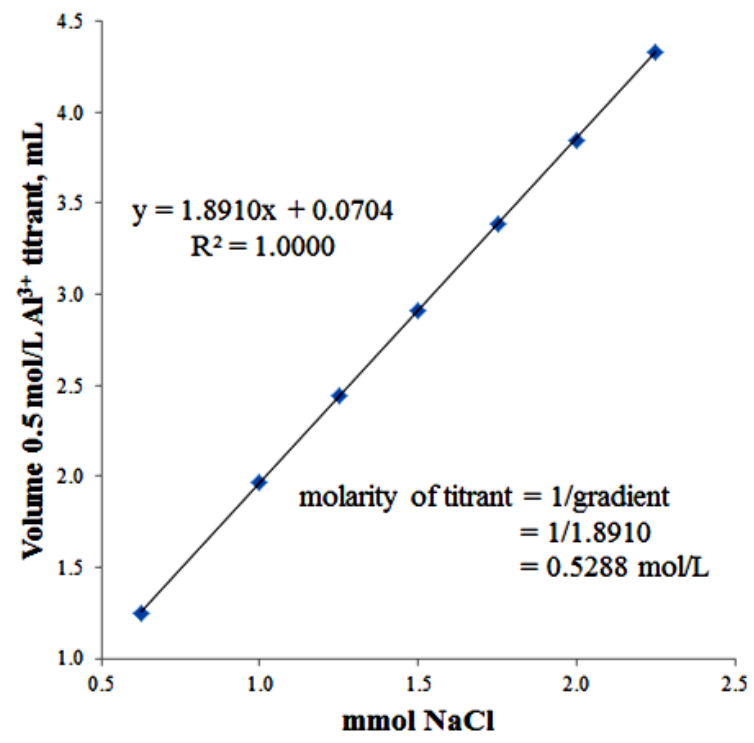

Figure 1. Illustration of regression analysis method of titrant molarity determination.

The systematic error of a titration encompasses all errors inherent in the determination. These errors may include in this instance (but may not be restricted to) traces of sodium in the reagents used in the determination, the difference between the instrumentally-determined end-point and that theoretically obtained under equilibrium conditions, delays in the detection of temperature changes in the solution, and processing delays in the electronics and software of the instrument. In practical terms, the systematic error needs only to be performed on each sample type under investigation during the setting-up phase, unless experimental conditions are changed at a later date. The methodology is analogous to the titrant standardization procedure outlined previously. A range of sample amounts are titrated, using the same quantities of reagents employed for the sample preparation and the titration itself. A plot of the sample amount (x axis) against the amount of titrant consumed (y axis) should yield a linear relationship after regression analysis. The y axis intercept is equivalent to the systematic error of the method. Except in the instance of a standard addition procedure, the systematic errors for the analysis of all samples reported here was determined.

\subsection{Sample Preparation}

This paper deals with the analysis of sodium in various foodstuffs. There are at least three principals evident in the preparation of a sample for titrimetric analysis:

1) The analyte must be fully liberated from the sample matrix, and be in a suitable condition so that it can react with the titrant;

2) The fluid containing the analyte is sufficiently mobile and non-viscous so that it can be rapidly mixed with the titrant, ensuring that the titration signal noise is not excessive;

3) That other constituents present in the fluid presented for titration do not prevent a reproducible stoichiometric endpoint from being found.

Given that the physical and chemical nature of foodstuffs varies enormously, the analyst must be able to use knowledge of the sample in order to devise a suitable sample preparation regime.

\subsection{Determination of Sodium in Dairy and Non-Dairy Milk Products}

The sodium content of such products is relatively low. The general procedure was modified to employ a standard addition of a fixed volume of a sodium solution, where the blank value of the standard addition is subtracted from that obtained from titration of the sample plus blank.

A $100 \mathrm{~mL}$ aliquot of milk was pipetted into a $250 \mathrm{~mL}$ Erlenmeyer flask containing $12.0 \mathrm{~g}$ trichloroacetic acid and a magnetic spin bar. The flask contents were then stirred for five minutes. The curdled milk was then filtered through a fast filtering paper. A $25 \mathrm{~mL}$ aliquot of the filtrate was then titrated with standardized $\mathrm{c}\left(\mathrm{Al}\left(\mathrm{NO}_{3}\right)_{3}\right)=0.5 \mathrm{~mol} / \mathrm{L}, \mathrm{c}\left(\mathrm{KNO}_{3}\right)=1.1 \mathrm{~mol} / \mathrm{L}$ solution after automated addition of $3 \mathrm{~mL} \mathrm{c}(\mathrm{NaCl})=0.25 \mathrm{~mol} / \mathrm{L}$ and $5 \mathrm{~mL} \mathrm{c}\left(\mathrm{NH}_{4} \mathrm{~F}\right)=40 \%(\mathrm{w} / \mathrm{v})$ solution. Note that since the aliquot is taken from a solution whose original volume has been enhanced by the addition of the trichloroacetic acid; this volume increase has to be taken into account when calculating the effective volume of original milk actually titrated.

It was found experimentally that the dissolution of 12 $\mathrm{g}$ trichloroacetic acid in $100 \mathrm{~mL}$ water increased the volume of solution to $106 \mathrm{~mL}$. Therefore, for example, a $25 \mathrm{~mL}$ aliquot of filtrate or centrifugate was equivalent to $25 \times 100 / 106=23.58 \mathrm{~mL}$ of original milk.

Table 1 lists results obtained in T.S' laboratory, as well as those by a colleague working in another laboratory using the same methodology.

\subsection{Determination of Sodium in "Two Minute" or "Instant" Noodle Snacks}

"Two minute" noodles are a popular snack. To prepare for eating, boiling water is poured onto a compressed noodle cake in the plastic container. Before eating the contents of a flavour sachet are stirred in. Successful analysis of the total sodium content requires that the sodium contents of the noodles and the flavouring are determined separately, the results being combined mathematically according to the respective masses of the components. Beside sodium chloride, other sources of sodium are present in the product. The following list of so- 
Table 1. TET analysis of total sodium content of soy and cow's milks.

\begin{tabular}{ccc}
\hline \multirow{2}{*}{ Sample } & \multicolumn{2}{c}{ mg Na/100g } \\
\cline { 2 - 3 } & $\begin{array}{c}\text { Nutritional } \\
\text { information-stated } \\
\text { average values (label) }\end{array}$ & Found by TET \\
\hline Soy milk \#1 & 25 & $24.9 \pm 0.2(\mathrm{n}=7)$ \\
Soy milk \#2 & 44 & $65.1 \pm 0.1(\mathrm{n}=8)$ \\
Soy milk \#3 & 60 & $61.2 \pm 0.8^{1}\left(\mathrm{AAS}=62.0^{2}\right)$ \\
Cow's milk & 40 & $44.4 \pm 0.4^{1}$ \\
\hline
\end{tabular}

Notes 1and 2: Results supplied by colleague working in another laboratory.

dium salts were found on the label of a popular brand of "two-minute" noodles (Table 2).

\subsubsection{Analysis of Dried Noodle Cake}

The mass of the entire noodle cake was determined and recorded. The cake was then roughly broken, and transferred quantitatively to the container of an inverted cup style of domestic blender, where it was reduced to the consistency of coarse flour. It was then turned out in its entirety onto a clean sheet of paper, where it was "coned and quartered" to obtain a representative sample. Approximately $2.5 \mathrm{~g}$ of sample was weighed accurately into a $75 \mathrm{~mL}$ polypropylene titration vessel, and $10 \mathrm{~mL}$ of $300 \mathrm{~g} / \mathrm{L}$ trichloroacetic acid solution added. The suspension was allowed to stand for a few minutes, then 10 $\mathrm{mL}$ acetone added, and the suspension homogenized with a high shear disintegrator at 20,000 rpm. The shaft of the disintegrator was washed with approximately $5 \mathrm{~mL}$ of a 1:1 acetone/water mixture into the titration vessel. Acetone was used to reduce the swelling of the starch grains, keeping the fluid mobile and easy to mix during the titration. The suspension was then titrated with standardized $\left.\mathrm{c}\left(\mathrm{Al}\left(\mathrm{NO}_{3}\right)_{3}\right)=0.5 \mathrm{~mol} / \mathrm{L}, \mathrm{cKNO}_{3}\right)=1.1 \mathrm{~mol} / \mathrm{L}$ solution after automated addition $5 \mathrm{~mL} \mathrm{c}\left(\mathrm{NH}_{4} \mathrm{~F}\right)=400 \mathrm{~g} / \mathrm{L}$ solution .

\subsubsection{Analysis of Flavour Sachet}

The mass of the entire contents of a flavour sachet was first determined and recorded. The material was then transferred quantitatively to a $500 \mathrm{~mL}$ volumetric flask, which was made to volume with deionized water and thoroughly mixed. To remove solids which might otherwise block volumetric pipettes used to take aliquots, the flask contents were filtered through a rapid flow quailtative filter paper. A $20 \mathrm{~mL}$ aliquot of the solution was then pipetted into a $75 \mathrm{~mL}$ polypropylene titration vessel, and $2 \mathrm{~mL}$ of concentrated hydrochloric acid added. The automated titration program added $5 \mathrm{~mL} \mathrm{c}\left(\mathrm{NH}_{4} \mathrm{~F}\right)=400$ $\mathrm{g} / \mathrm{L}$ solution before being titrated with standardized $\mathrm{c}\left(\mathrm{Al}\left(\mathrm{NO}_{3}\right)_{3}\right)=0.5 \mathrm{~mol} / \mathrm{L}, \mathrm{c}\left(\mathrm{KNO}_{3}\right)=1.1 \mathrm{~mol} / \mathrm{L}$ solution.
Table 2. Food code numbers for sodium sources in "two minute” noodle snacks.

\begin{tabular}{cc}
\hline Food Code Number & Sodium source \\
\hline- & Sodium chloride \\
451 & Pentasodium triphosphate \\
500 & Sodium carbonates \\
621 & Monosodium glutamate \\
635 & Disodium ribonucleotides \\
\hline
\end{tabular}

The final total sodium content of the snack pack was computed from the sodium contents and masses of the components. Table 3 compares the manufacturer's stated analysis values with those determined by TET analysis.

It is unknown how the manufacturer determines the total average values of the products, but it may be noted that if the sodium value for the noodle cake is subtracted from the TET results, the TET results would have been in much closer agreement.

Typical titration plots for the analysis of sodium in the compressed noodle cake and the flavour sachet are illustrated in Figures $\mathbf{2}$ and $\mathbf{3}$.

The inflection in the solution temperature curve denotes the endpoint. This is located accurately by the second derivative of the digitally-smoothed solution temperature curve. The degree of digital smoothing can be adjusted in the titration software.

\subsection{Determination of Sodium in Processed Cheeses}

Cheese products such as processed cheeses may contain various sodium salts aside from sodium chloride which are added during manufacturing in order to obtain a product of the desired characteristics. In these cheeses, protein, fat and water are combined into a homogenous mass, meaning that careful attention must be given to fully liberating sodium ion from the matrix. Grated and sliced cheeses from a number of manufacturers were purchased for the tests. Based on the anticipated sodium content of the sample, between 2 to $5 \mathrm{~g}$ of grated or finely sliced cheese was weighed into a $75 \mathrm{~mL}$ polypropylene titration vessel. To aid in the liberation of the sodium, $10 \mathrm{~mL}$ of $300 \mathrm{~g} / \mathrm{L}$ trichloroacetic acid solution was added, together with $10 \mathrm{~mL}$ of deionized water. The sample was dispersed for 30 seconds at 20,000 rpm using a high shear disintegrator. A milky fluid resulted. To prevent later fouling of the titration apparatus, $5 \mathrm{~mL}$ of toluene was then added to assist in solubilizing the fat. The sample was then subjected to another 30 seconds of disintegration. Finally, the disperser head was carefully washed with approximately $10 \mathrm{~mL}$ of deionized water into the titration vessel. 
Table 3. Comparison of manufacturer-stated average values with TET-analyzed values.

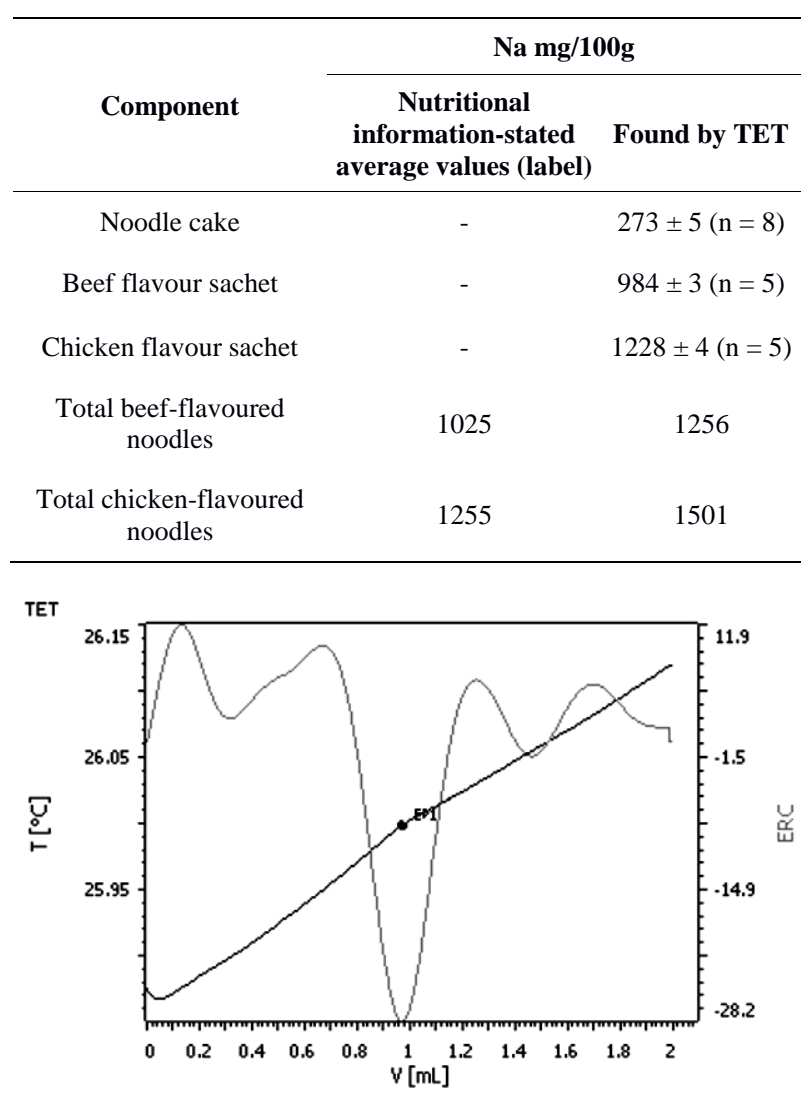

Figure 2. TET titration plot-sodium in noodle cake in "two minute" noodle snack pack.

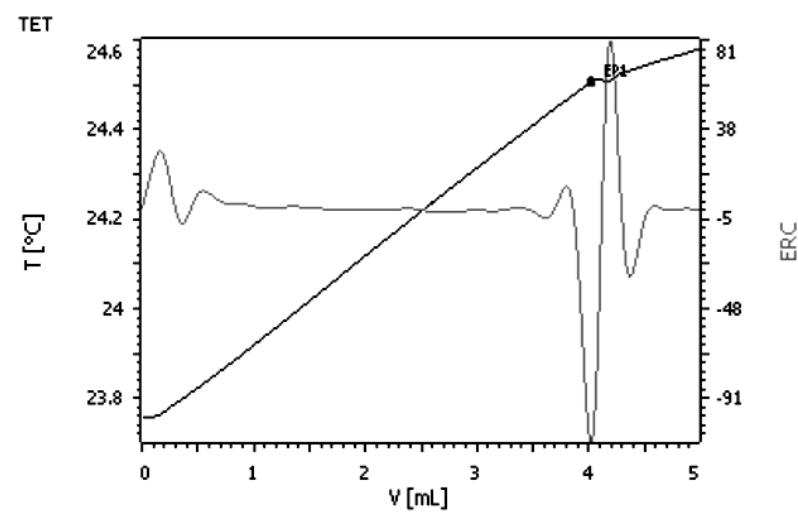

Figure 3. TET Titration plot-sodium in flavour sachet of "two minute" noodle snack.

At the beginning of the automated titration program, 5 $\mathrm{mL} \mathrm{c}\left(\mathrm{NH}_{4} \mathrm{~F}\right)=400 \mathrm{~g} / \mathrm{L}$ solution was added. The titration then proceeded with standardized $\mathrm{c}\left(\mathrm{Al}\left(\mathrm{NO}_{3}\right)_{3}\right)=0.5$ $\mathrm{mol} / \mathrm{L}, \mathrm{c}\left(\mathrm{KNO}_{3}\right)=1.1 \mathrm{~mol} / \mathrm{L}$ solution as titrant. Table 4 lists a comparison between the manufacturer's stated average values, and those found by TET.

Although the values cited by the manufacturers can be regarded as average values only and can be expected to
Table 4. Comparison of manufacturer-stated average values with TET-analyzed values.

\begin{tabular}{ccc}
\hline & \multicolumn{2}{c}{ Na mg/100g } \\
\cline { 2 - 3 } Cheese sample & $\begin{array}{c}\text { Nutritional } \\
\text { information-stated } \\
\text { average values (label) }\end{array}$ & Found by TET \\
\hline Shredded parmesan & 1060 & $986 \pm 3(\mathrm{n}=5)$ \\
Shredded tasty cheese & 610 & $732 \pm 5(\mathrm{n}=5)$ \\
"Light” cheese slices & 600 & $684 \pm 3(\mathrm{n}=5)$ \\
“Colby” slices & 668 & $725 \pm 9(\mathrm{n}=5)$ \\
\hline
\end{tabular}

vary according to the degree of process control imposed, three of the four samples exhibited a positive bias when analyzed by TET. The potential for interference by other ions which form similar compounds to elpasolite $\mathrm{NaK}_{2} \mathrm{AlF}_{6}$ has to be considered. Calcium is an important component of milk products. Calcium is also known to form $\mathrm{KCaAlF}_{6}$, an "elpasolite" type of compound. Tri- chloroacetic acid is known to liberate calcium by its de- naturing effect on calcium caseinate, and has been used for this purpose in the determination of calcium in milk products. Calcium therefore has the potential to interfere in the determination of sodium by the TET "elpasolite" method.

An experiment was set up, whereby increasing amounts of calcium were added to a fixed amount of sodium, with both ion solutions dosed by precision automatic burettes. Amounts of calcium (as $\mathrm{CaCl}_{2}$ ) ranging from 0 to $2.5 \mathrm{mmol}$ were dosed to $1.25 \mathrm{mmol}$ sodium as $\mathrm{NaCl}$, and then titrated with $\mathrm{c}\left(\mathrm{Al}\left(\mathrm{NO}_{3}\right)_{3}\right)=0.5 \mathrm{~mol} / \mathrm{L}$, $\mathrm{c}\left(\mathrm{KNO}_{3}\right)=1.1 \mathrm{~mol} / \mathrm{L}$ solution after adding $2 \mathrm{~mL}$ concentrated $\mathrm{HCl}$ and $5 \mathrm{~mL} \mathrm{c}\left(\mathrm{NH}_{4} \mathrm{~F}\right)=400 \mathrm{~g} / \mathrm{L}$ solution. Figure 3 illustrates the effect of increasing the molar ratio $[\mathrm{Ca}] /[\mathrm{Na}]$ on the error in determining the sodium content of the solution.

It may be observed that until a molar ratio of $[\mathrm{Ca}] /[\mathrm{Na}]$ of approximately 0.5 is reached, there is a negligible effect on the error in determining the sodium value. Thereafter, the increase is approximately linear. To put these results into context, the $[\mathrm{Ca}] /[\mathrm{Na}]$ molar ratios for a random selection of commercial cheeses were calculated, based on the average values given on the packages. These values are listed in Table 5.

By reference to Table 5 and Figure 4, it may be observed that the highest $[\mathrm{Ca}] /[\mathrm{Na}]$ molar ratio results in an error in the determined value of the sodium content of approximately $1 \%$ of that value. This is likely to be well within the variations in the sodium value during manufacture, and a decision could be made to neglect this error for routine process control.

An analytical recovery test for the determination of sodium in processed cheeses was performed by a colleague working in a third laboratory. Known amounts of 
Table 5. $[\mathrm{Ca}] /[\mathrm{Na}]$ molar ratios in some commercial cheeses.

\begin{tabular}{cccc}
\hline Cheese & Na mg/100 g & Ca mg/100 g & [Ca]/[Na] \\
\hline Grated parmesan & 1000 & 550 & 0.32 \\
Processed "tasty" cheese & 640 & 732 & 0.66 \\
Processed "swiss" slices & 470 & 600 & 0.73 \\
Mozzarella & 475 & 700 & 0.85 \\
\hline
\end{tabular}

sodium chloride were added to a previously analyzed sample of a spreadable cream cheese. Analytical recoveries ranged from $99.5 \%$ - $102.6 \%$ over seven separate determinations, with a mean recovery of $100.0 \%$.

\subsection{Determination of Sodium in Canned Fish Products}

"Snack packs" of canned fish are a popular luncheon choice. From a point of view of sample preparation, it is necessary to liberate all sodium from a matrix which possesses high protein content. In this instance, the entire contents of a small can of fish snack were transferred to the cup of a domestic kitchen blender which had been rinsed with deionized water and dried. The fish product was blended until a smooth mass was obtained, from which no water separated. Approximately $10 \mathrm{~g}$ of this homogenate was weighed into a $75 \mathrm{~mL}$ polypropylene titration vessel, and $15 \mathrm{~mL}$ deionized water and $5 \mathrm{~mL}$ of $\mathrm{c}\left(\mathrm{CCl}_{3} \mathrm{COOH}\right)=300 \mathrm{~g} / \mathrm{L}$ trichloroacetic acid solution added. The vessel contents were subjected to high shear homogenisation at 20,000 rpm for 60 seconds. The head of the disintegrator was carefully washed with minimum deionized water into the titration vessel, which was then placed in the rack of an automatic sample processor. The automated titration program commenced with dosing of $\mathrm{c}\left(\mathrm{NH}_{4} \mathrm{~F}\right)=400 \mathrm{~g} / \mathrm{L}$ ammonium fluoride solution, followed by titration with $\mathrm{c}\left(\mathrm{Al}\left(\mathrm{NO}_{3}\right)_{3}\right)=0.5 \mathrm{~mol} / \mathrm{L}, \mathrm{c}\left(\mathrm{KNO}_{3}\right)=$ $1.1 \mathrm{~mol} / \mathrm{L}$ solution. The results of analysis are listed in Table 6.

\section{CONCLUSION}

The examples illustrated here are not exhaustive of the range of the technique. Other foodstuffs which have been successfully analyzed include dry snack foods as potato and corn chips crackers and pretzels, sauces, soups and marinades, as well as the sodium in the "overrun” fluid used in the manufacture of margarine. The practical detection limit of the procedure is governed by the amount of sample which can be successfully processed and presented to the instrument for analysis, but the sodium content of most foodstuffs lies within the range of analysis. Application of the procedure also depends on the ability to devise a suitable sample preparation procedure to liberate the sodium from the sample matrix in such a
Table 6. Analysis of tuna fish snack for sodium by TET.

\begin{tabular}{ccc}
\hline \multirow{2}{*}{ Sample } & \multicolumn{2}{c}{ Na mg/100g } \\
\cline { 2 - 3 } & $\begin{array}{c}\text { Nutritional } \\
\text { information-stated } \\
\text { average values (label) }\end{array}$ & Found by TET \\
\hline $\begin{array}{c}\text { "Chunk-style tuna in } \\
\text { natural spring water" }\end{array}$ & 253 & $236 \pm 2.1(\mathrm{n}=5)$ \\
\hline
\end{tabular}

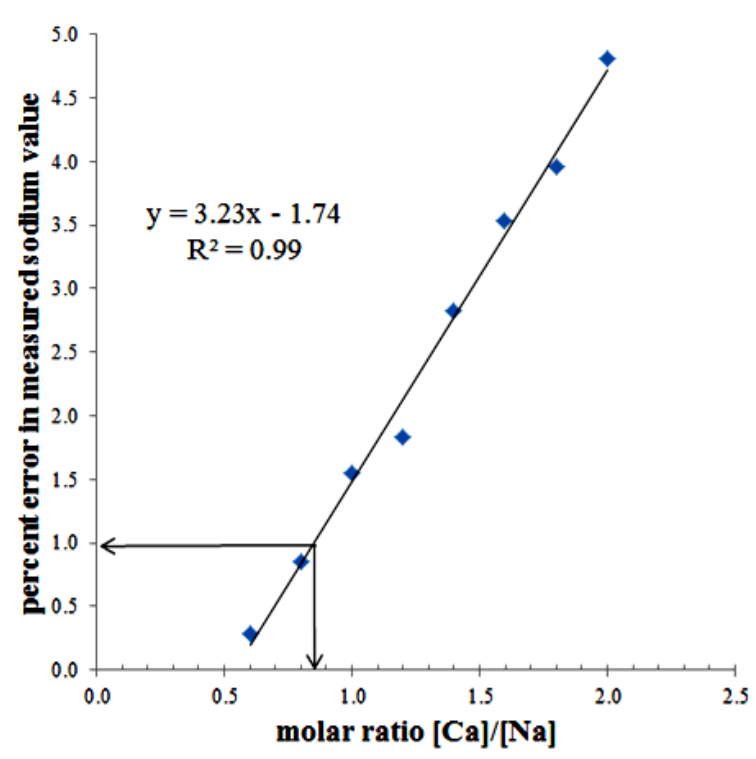

Figure 4. Effect of $[\mathrm{Ca}] /[\mathrm{Na}]$ molar ratio on the percentage error in determining the sodium content.

fashion that it can be titrated reliably. The titration itself is robust and reliable.

\section{ACKNOWLEDGEMENTS}

The authors wish to thank Darina Mestman Rosen of Dr. Golik Chemical Instrumentation, Israel, and Angelika Kilast of Deutsche Metrohm GmbH \& Co., KG, Germany, for kindly providing some of the analytical results used in this paper.

\section{REFERENCES}

[1] Sen, B. (1957) Indirect complexometric titration of sodium and potassium with EDTA. Fresenius' Zeitschrift für Analytische Chemie, 157, 2-6.

[2] Dobbins, J.T. and Byrd, R.M. (1931) A volumetric method of determining sodium. Journal of the American Chemical Society, 53, 3288-3291 http://dx.doi.org/10.1021/ja01360a011

[3] Carr, J.D. and Swartzfager, D.G. (1970) Complexometric titration for the determination of sodium ion. Analytical Chemistry, 42, 1238-1241. http://dx.doi.org/10.1021/ac60293a025

[4] I. Sajó. (1969) Magyar Kemiai Folyoirat, 75, 1-3. 